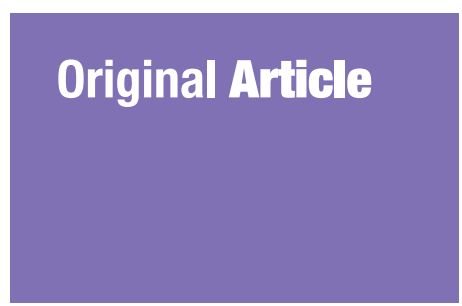

Submitted: 23 Mar 2016 Accepted: 3 Dec 2016 Online: 24 Feb 2017

\section{Postpartum Sexual Functioning and Its Predicting Factors among Iranian Women}

\author{
Nazanin Rezaei ${ }^{1}$, Arman Azadi ${ }^{2}$, Kourosh Sayehmiri ${ }^{1}$, Reza \\ VALIZADEH $^{3}$
}
$1 \quad$ Psychosocial Injuries Research Center, Ilam University of Medical Sciences, Ilam, Iran
2 Department of Nursing, Faculty of Nursing and Midwifery, Ilam University of Medical Sciences, Ilam, Iran
$3 \quad$ Psychiatry Department, Schools of Medicine, Ilam University of Medical Sciences, Ilam, Iran

\author{
Sciences, Ilam, Iran
}

To cite this article: Rezaei N, Azadi A, Sayehmiri K, Valizadeh R. Postpartum sexual functioning and its predicting factors among Iranian women. Malays J Med Sci. 2017;24(1):94-103. https://doi.org/10.21315/mjms2017.24.1.10

To link to this article: https://doi.org/10.21315/mjms2017.24.1.10

\title{
Abstract
}

Background: Many women experience sexual dysfunction following childbirth but this has not been well investigated in Iran. The aim of this study was to evaluate women's sexual function in the postpartum period in Iran. It also sought to determine predicting factors associated with their sexual function.

Methods: This was a cross-sectional study among 380 postpartum women attending 10 urban health centers in Ilam province in southwestern Iran. Participants were selected using random cluster sampling. Data was collected using the female sexual function index (FSFI) and a checklist of socio-demographic and maternal status for each of the women. Sexual dysfunction was classified according to an FSFI score of $\leq 28$. Data were analysed using SPSS version 22. Results: The majority of participants (76.3\%) had sexual dysfunction. Primiparity (adjusted odds ratio (aOR): 1.78 (95\% Confidence Interval (CI): 1.11, 2.94); $P=0.006$ ) and exclusive breastfeeding (aOR: 2.47 (95\% CI: 1.21, 5.03); $P=0.012)$ were associated with increased odds of experiencing sexual dysfunction in the postpartum period. Other factors such as age, type of delivery, education, time since delivery and family income did not predict women's postpartum sexual function.

Conclusion: This study confirmed findings of previous studies on factors that may have an adverse effect on new mothers' sexual function in the postpartum period. However the effect of type of delivery on postpartum sexual function remains unclear.

Keywords: postpartum, women, sexual function, childbirth, Iran

\section{Introduction}

Pregnancy and labour herald a multitude of changes for women in their sense of well-being and their quality of life for women; these changes include physical, psycho-social and cultural changes (1-3). Most new mothers experience perineal pain, tiredness, depression, urinary incontinence and altered sexual function (4). Changes in sexual function are prevalent in the postpartum period (5). However, this problem is not usually discussed in postnatal visits and has received little consideration from both healthcare providers and researchers (6). Generally, most women recommence sexual activity within 3-6 months of delivery and report sexual function comparable to that before pregnancy $(4,7)$. However, sexual dysfunction in the postpartum period is common in $41 \%-83 \%$ of women during the first 3 months after childbirth $(5,6,8,9)$.

According to the findings of previous studies, concern about becoming pregnant again, breastfeeding and vaginal delivery are factors that may postpone resumption of sexual 
activity in some women. For example, in the past three decades has seen an increase in the rate of caesarean section (CS) and this has been attributed to the protective effects of CS on early resumption of sexual activity (10). However, the results of some other studies have shown that CS had no protective impact on resuming sexual function compared to NVD $(6,11-14)$. In addition to the conflicting results of previous studies regarding the effect of type of labour on sexual function, other influential factors that may predict postpartum sexual function have not been well investigated to date.

According to the World Health Organization, the postpartum period may represent an ideal time for information and/ or counseling on sexual life and identifying the 'needs of women' regarding sexual health and functioning (15). However, the findings of previous studies show that almost $15 \%$ of women with postpartum sexual problems were able to discuss it with their healthcare providers (16, 17). In addition, postpartum sexual problems have received little attention from clinicians, and postnatal follow-ups mainly concentrate on vaginal examination or contraception and other health concerns are overlooked (18). However, sexual issues need to be addressed with sensitivity to cultural differences and religious status because women show diverse patterns of sexual dysfunction according to ethnic and racial context. For example, in Nigeria, it is a deep rooted cultural practice to avoid sexual intercourse after delivery until the child is fully weaned and no longer breastfeeding (4). In Iran, religious and cultural values dictate that many women with sexual dysfunction do not consult with a healthcare provider, therefore the problem remains under-recognised $(19,20)$. It has been estimated that prevalence of sexual disorder among Iranian women ranges from $27 \%$ to $44 \%$ $(11,17,19,21)$. Some published studies have demonstrated that female sexual dysfunction is common in the general population in Iran especially among couples with poor educational background or in a low socioeconomic class (17, 19). In addition, it has been estimated that $50 \%$ of divorces cases among Iranian couples may have roots in low level sexual satisfaction (20).

To the best of our knowledge, few researches have been done in Iran to provide data regarding women's sexual function during the postpartum period. Previous related studies in Iran and other Asian countries have mainly focused on pain during sexual activity and the effect of type of delivery on postpartum sexual function. Although earlier findings showed that most women resumed sexual activity two months after delivery, the predicting factors associated with early resumption of sexual activity have not been well investigated to date. Furthermore, as noted previously, sexual function is a notion that relates to religion and culture. For example, in Iran and some other Muslim countriesespecially in the context of this studyresumption of sexual activity within six weeks postpartum is normally prohibited based on cultural and religious beliefs. Hence, the findings of studies in developed countries are often not appropriate to Asian and Middle East countries. The purpose of this study was to examine sexual function among Iranian women in the postpartum period. It also sought to determine predicting factors associated with their sexual function.

\section{Materials/Subjects and Method}

\section{Study design}

This cross-sectional study was carried out in 10 urban health centers in Ilam province in southwestern Iran.

\section{Study population}

The study population consisted of women who met the following criteria: (a) > eight weeks and < eight months post-delivery (14); (b) age $\geq 18$ years old; (c) delivery at week 38 to 42 ; (d) resident in Ilam city in the previous year; (e) couples with no history of surgery in the past 3 months; (f) couples with no history of lesions or other genital injury (based on medical records), which might cause difficulty during intercourse; and (g) willingness to participate in the study. Women with obstetric/neonatal complications related to the current birth, women with postpartum depression and women with disabling chronic illness were excluded from the study.

\section{Selection of study subjects}

Sampling was performed using random cluster sampling. Firstly, participants were clustered according to the five geographical regions of Ilam city (North, South, East, West and Center). Then two urban health centres were selected randomly from each cluster. Since there were different numbers of households in each urban health centre, proportional random sampling was used to determine the sample size 
of each of the 10 centres. After reviewing family health records, women who satisfied the study requirements were recognised and those eligible were selected randomly and invited to take part in the study. The sample size was calculated by considering the estimated prevalence of sexual dysfunction. Based on prevalence of postpartum sexual dysfunction at $44 \%(11,17,19,21)$ and 95\% confidence interval and using the following formula, the sample size was calculated at 378 subjects.

$$
n=\frac{Z_{1-a / 2}^{2} p(1-p)}{d^{2}}=378
$$

Considering subject attrition of $10 \%, 420$ eligible women were randomly selected and invited to participate in the study. Overall, 380 cases were enrolled in the study and filled out the questionnaire (response rate $=90 \%$ ).

\section{Study instrument}

The instrument for data collection consisted of two sections. The first part included the sociodemographic and maternal status of women and was filled out according to statements made by participants or medical record data from the health centre. Demographic data included age, number of living children, type of delivery, breast feeding status, occupation, disease history, level of educational and history of divorce. Those mothers who had exclusively breastfed for the first six months of their baby's life (or until participation in current study for those with less than six months since delivery) without using formula feed were considered as breastfeeding women (6). Financial status was defined as their family's monthly income. They were asked to report their financial status as income less than cost, income equal to cost and income more than cost. The second part was the female sexual function index (FSFI) (22). The FSFI is a brief self-report scale of women's sexual function. This scale was composed of six subscales with 19 items that assess a woman's sexual function during the previous month; sexual desire (2 questions), orgasm (3 questions), lubrication (4 questions), arousal (4 questions), satisfaction (3 questions) and pain (3 questions). In this questionnaire, each item was given a score o to 5, except for questions 1, 2, 15 and 16 that were scored from 1 to 5 . A score of zero in each of domain indicated no sexual intercourse in the previous month. For each of the 6 domains, a score was calculated by summing up the scores of that domain's questions. Next, the sum of each domain's scores was multiplied by the domain factor in the FSFI. The multiplier factors for domains of desire, orgasm/satisfaction/pain and arousal/lubrication were $0.6,0.4$ and 0.3 , respectively. The overall scale score ranged from 2 to 36 . Having a lower score on each of the FSFI domains or on the whole scale suggested poorer sexual function. FSFI scores $\leq 28$ was classified as sexual dysfunction. In addition, each domain that acquired less than $65 \%$ of total scores of that domain was considered as sexual dysfunction. Consequently, a score lower than 3.9 in each of the FSFI domains was considered sexual dysfunction (11). The findings of numerous validation studies have shown that the FSFI has satisfactory reliability and validity indices (2327). Reliability and validity of the Iranian version of FSFI was assessed in Iran $(26,27)$. Internal consistency was evaluated using Cronbachalpha coefficient in each of the six domains of the scale. The value of the coefficient ranged from 0.72 to 0.90 , which indicated acceptable to good consistency $(26,27)$.

Accuracy and clarity verification of FSFI was made by two skilled translators in English and Persian languages. The face and content validity of the FSFI was appraised and confirmed by a panel of experts consisting of 12 academic affairs of Ilam University of Medical Sciences, Ilam, Iran. Furthermore, to confirm reliability of the final version of the questionnaire a pilot study was conducted on 25 postpartum women. Cronbach-alpha coefficient values for each domain of the scale ranged from 0.70 to 0.85 .

\section{Ethical issues and data collection}

Prior to data collection, the proposal of this study was approved by the local-regional ethics committee of Ilam University of Medical Sciences (EC/93/H/259). Next, the researchers referred to urban health centres from March 2014 to June 2015. Then, after having the aim of the study described to them, participants were invited to attend a personal interview for data collection. Interviews were performed by a female interviewer in locations preferred by the subjects. Prior to the study, all women provided informed consent for voluntary participation in the study.

\section{Statistical analysis}

Statistical analysis was performed using SPSS version 22. The demographic/healthrelated data of women was reported using descriptive statistics such as a percentage, mean 
Original Article | Postpartum sexual functioning and its predicting

and standard deviation. Univariate analysis was made using Pearson chi-square/Fisher's exact test to determine association between the demographic/obstetric characteristics of each participant with sexual dysfunction. The predictors of women sexual dysfunction were determined using stepwise multivariable logistic regression. The input variables to the model (assumed predictors of sexual dysfunction) included age (the risk is described for every one year increase in age), parity (multiparous versus primiparous), exclusive breastfeeding, education ( $\leq 12$ years versus $>12$ ), income (income $\geq$ expense versus income $<$ expense), time since birth ( $\leq 3$ months versus $>3$ months), and type of delivery (CS versus NVD). A value of $P<0.05$ was considered statistically significant.

\section{Results}

Three hundred and eighty women were enrolled in the study. Of those, 93 (24.5\%) were at 8 to 12 weeks postpartum, 153 (40.3\%) were at 3 to 5 months postpartum and 134 (35.3\%) were at 6 to 8 months postpartum. There was no significant difference between demographic/ maternal characteristics of respondent and nonrespondent women. Mean (SD) of the overall FSFI score was 22.24 (7.93). The majority of participants (76.3\%) experienced sexual dysfunction (FSFI scores $\leq 28$ ). In total, 38 $(10 \%)$ of women reported no sexual activity in the past 4 weeks; of those, 24 (63\%) were 8 to 12 weeks into the postpartum period.

Mean (SD) age of subjects was 29.81 (5.5) years. Most women were housewives (77.6\%), and about half of them (44.7\%) had a college degree. More than half of them (61.3\%) reported that their monthly income was insufficient to cover their expenses. Also, about half of the women were primiparous (53.1\%). Type of delivery among primiparous women was mainly caesarian $(61.3 \%)$. The rate of caesarian delivery was higher among those with a college degree, those who were primiparous and those women who had a higher household income.
Table 1 shows comparisons of participants' characteristics according to their sexual dysfunction. As shown in this table, women with sexual dysfunction were more likely to be older (> 30 years), primiparous, housewives, less educated with lower income and had breastfeed their babies. Sexual functioning did not differ by mode of delivery or by whether an episiotomy had been performed.

Lack of sexual desire was the most prevalent dysfunction, reported by $79 \%$ of the women. Table 2 shows frequency of sexual dysfunction in 6 domains of FSFI according to demographic/ maternal characteristics. As shown in this table, there was a significant difference between age of participant and sexual problem in arousal and orgasm subscales. Also, there was significant difference between time since labour and sexual dysfunction in the orgasm, satisfaction and pain domains. Sexual dysfunction in the domains of arousal, lubrication, satisfaction and pain was significantly higher among women who had breast fed their babies. There was a significant difference between parity and sexual dysfunction, except for in the domains of lubrication and pain. There were no significant relationships determined between domains of sexual dysfunction and mode of delivery, education, financial status and job.

Table 3 shows the input variables that were tested using multivariate logistic regression analysis and recognised as statistically significant predictors of women sexual function. Briefly, the results revealed that postpartum sexual function was determined by parity and exclusive breast feeding. In other words, primiparity and exclusive breastfeeding were associated with increased odds of having sexual dysfunction in the postpartum period. Women who had exclusively breastfed their babies and primiparous mothers being 2.47 times (aOR: 2.47 (95\% CI: 1.21, 5.03); $P=0.012$ ) and 1.78 times (aOR: 1.78 (95\% CI: 1.11, 2.94); $P=$ 0.006) as likely to experience sexual dysfunction compared to non-breastfeeding mothers, respectively. Factors that did not predict postpartum sexual function were type of delivery, 
Table 1. Socio-demographic and maternal characteristics of participants

\begin{tabular}{|c|c|c|c|}
\hline \multirow[b]{2}{*}{ Variables } & \multicolumn{2}{|c|}{ Sexual dysfunction } & \multirow[b]{2}{*}{$P$-value ${ }^{\text {a }}$} \\
\hline & $\begin{array}{c}\text { Yes } \\
n(\%)\end{array}$ & $\begin{array}{c}\text { No } \\
n(\%)\end{array}$ & \\
\hline $\begin{array}{l}\text { Age (years) } \\
\leq 30 \\
>30\end{array}$ & $\begin{array}{l}122(42.1) \\
168(57.9)\end{array}$ & $\begin{array}{l}56(62.2) \\
34(37.8)\end{array}$ & 0.001 \\
\hline $\begin{array}{l}\text { Education (years) } \\
\leq 12 \\
>12\end{array}$ & $\begin{array}{l}165(56.9) \\
125(43.1)\end{array}$ & $\begin{array}{l}45(50.0) \\
45(50.0)\end{array}$ & 0.152 \\
\hline $\begin{array}{l}\text { Financial status } \\
\text { Income }<\text { expense } \\
\text { Income } \geq \text { expense }\end{array}$ & $\begin{array}{l}184(63.4) \\
106(36.6)\end{array}$ & $\begin{array}{l}49(54.4) \\
41(45.6)\end{array}$ & 0.080 \\
\hline $\begin{array}{l}\text { Job } \\
\text { Housewife } \\
\text { Employed }\end{array}$ & $\begin{array}{c}230(79.3) \\
60(20.7)\end{array}$ & $\begin{array}{l}65(72.2) \\
25(27.8)\end{array}$ & 0.104 \\
\hline $\begin{array}{l}\text { Parity } \\
\text { Primiparous } \\
\text { Multiparous }\end{array}$ & $\begin{array}{l}164(56.6) \\
126(43.4)\end{array}$ & $\begin{array}{l}38(42.2) \\
52(57.8)\end{array}$ & 0.012 \\
\hline $\begin{array}{l}\text { Time since birth (months) } \\
<3 \\
3-6 \\
>6\end{array}$ & $\begin{array}{c}76(26.2) \\
117(40.3) \\
97(33.4)\end{array}$ & $\begin{array}{l}17(18.9) \\
36(40.0) \\
37(41.1)\end{array}$ & 0.266 \\
\hline $\begin{array}{l}\text { Exclusive breastfeeding } \\
\text { Yes } \\
\text { No }\end{array}$ & $\begin{array}{c}264(91.0) \\
26(9.0)\end{array}$ & $\begin{array}{l}75(83.3) \\
15(16.7)\end{array}$ & 0.035 \\
\hline $\begin{array}{l}\text { Type of delivery } \\
\mathrm{NVD}^{\mathrm{b}} \\
\mathrm{CS}^{\mathrm{c}}\end{array}$ & $\begin{array}{l}110(37.9) \\
180(62.1)\end{array}$ & $\begin{array}{l}37(41.1) \\
53(58.9)\end{array}$ & 0.337 \\
\hline
\end{tabular}

${ }^{a}$ Based on chi-square/ Fisher's exact test

${ }^{\mathrm{b}}$ Normal vaginal delivery

${ }^{\mathrm{c}}$ Caesarian section

Table 2. Frequency of sexual dysfunction items by demographic/maternal characteristics ${ }^{\mathrm{a}}$

\begin{tabular}{|c|c|c|c|c|c|c|}
\hline & & Sexual & dysfunction $\mathrm{i}$ & n FSFI Don & nains & \\
\hline & $\begin{array}{c}\text { Sexual desire } \\
n(\%)\end{array}$ & $\begin{array}{c}\text { Arousal } \\
n(\%)\end{array}$ & $\begin{array}{c}\text { Lubrication } \\
n(\%)\end{array}$ & $\begin{array}{c}\text { Orgasm } \\
n(\%)\end{array}$ & $\begin{array}{c}\text { Satisfaction } \\
n(\%)\end{array}$ & $\begin{array}{l}\text { Pain } \\
n(\%)\end{array}$ \\
\hline $\begin{array}{l}\text { Age (years) } \\
\leq 30 \\
>30\end{array}$ & $\begin{array}{l}144(80.5) \\
165(81.7)\end{array}$ & $\begin{array}{c}87(48.9) * \\
117(57.9)\end{array}$ & $\begin{array}{l}60(33.7) \\
73(36.1)\end{array}$ & $\begin{array}{l}61(34.3))^{*} \\
90(44.6)\end{array}$ & $\begin{array}{l}45(25 \cdot 3) \\
66(32.7)\end{array}$ & $\begin{array}{c}78(43.8) \\
100(49.5)\end{array}$ \\
\hline $\begin{array}{l}\text { Time since birth } \\
\text { (months) } \\
<3 \\
3-6 \\
>6\end{array}$ & $\begin{array}{l}77(82.8) \\
127(83.0) \\
105(78.4)\end{array}$ & $\begin{array}{l}55(59.1) \\
76(49.7) \\
72(53.7)\end{array}$ & $\begin{array}{l}42(45.2) \\
50(32.7) \\
41(30.6)\end{array}$ & $\begin{array}{l}47(50.5) * \\
57(37.3) \\
47(35.1)\end{array}$ & $\begin{array}{c}42(45.2) * * \\
36(23.5) \\
33(24.6)\end{array}$ & $\begin{array}{c}59(63.4)^{* *} \\
63(41.2) \\
56(41.8)\end{array}$ \\
\hline $\begin{array}{l}\text { Exclusive breastfeeding } \\
\text { Yes } \\
\text { No }\end{array}$ & $\begin{array}{l}275(81.1) \\
34(82.9)\end{array}$ & $\begin{array}{c}192(56.6) * * \\
11(26.8)\end{array}$ & $\begin{array}{c}126(37.2) * \\
7(17.1)\end{array}$ & $\begin{array}{c}140(41.3) \\
11(26.8)\end{array}$ & $\begin{array}{c}105(31.0) * \\
6(14.6)\end{array}$ & $\begin{array}{c}166(49.0) \\
* \\
12(29.3)\end{array}$ \\
\hline $\begin{array}{l}\text { Parity } \\
\text { Multiparous } \\
\text { Primiparous }\end{array}$ & $\begin{array}{l}136(76.4) \\
165(81.7)\end{array}$ & $\begin{array}{l}86(48.3) * \\
118(58.4)\end{array}$ & $\begin{array}{c}62(34.8) \\
71(35.1)\end{array}$ & $\begin{array}{l}66(37.1) \\
85(42.1)\end{array}$ & $\begin{array}{c}45(25.3) * \\
68(33.7)\end{array}$ & $\begin{array}{l}80(44.9) \\
98(48.5)\end{array}$ \\
\hline
\end{tabular}

a Based on chi-square/ Fisher's exact test

${ }^{*} P<0.05,{ }^{* *} P<0.01$. 
Original Article | Postpartum sexual functioning and its predicting

Table 3. Predictors of sexual dysfunction in the postpartum period

\begin{tabular}{lcccc} 
& \multicolumn{2}{c}{ Binary logistic regression } & \multicolumn{2}{c}{ Multiple logistic regression } \\
Parameter & OR $(95 \% \mathrm{CI})$ & $P$-value & aOR $(95 \% \mathrm{CI})$ & $P$-value \\
Age $^{\mathrm{a}}$ & $1.03(0.99,1.08)$ & 0.119 & - & - \\
Exclusive breastfeeding & $2.03(1.02,4.03)$ & 0.043 & $2.47(1.21,5.03)$ & 0.012 \\
Primiparous & $1.78(1.11,2.94)$ & 0.018 & $1.96(1.21,3.27)$ & 0.006 \\
NVD $^{\mathrm{b}}$ & $1.14(0.70,1.85)$ & $0.589^{\mathrm{c}}$ & $1.21(0.74,1.98)$ & 0.447 \\
Education: $<12$ years & $1.33(0.82,2.12)$ & 0.251 & - & - \\
Income: income $<$ expense & $1.47(0.90,2.38)$ & 0.127 & - & - \\
Time since birth: $<3$ months & $1.53(0.84,2.77)$ & 0.160 & - & - \\
\hline
\end{tabular}

aOR, adjusted odds ratio; CI, confidence interval; OR, odds ratio.

The symbol- indicates those factor were not significant in the final analysis.

${ }^{a}$ OR described for every one year increase in age

b Normal vaginal delivery

${ }^{\mathrm{c}}$ Although cesarean delivery was not significant, this factor was included in the final analysis.

education, time since delivery and household income.

\section{Discussion}

The aim of this study was to evaluate mothers' sexual functioning in the postpartum period and its relationship with socio-maternal factors. To the best of our knowledge, this is one of the first studies in Iran to assess women's sexual functioning in the postpartum period and its predicting factors. Findings of the study showed that the majority of participants (76.3\%) had sexual dysfunction; this figure was higher than the prevalence of postpartum sexual dysfunction reported by other researchers in Iran. For example, rates of postpartum sexual dysfunction reported in other studies were about half of the population as shown in some other studies in Iran $(13,28)$. In a study in Brazil, sexual dysfunction was reported at 43\% among postpartum women (29). Several studies have shown similar results at rates of $41 \%-83 \%$ of postpartum women. $(2,4-6,8$, 9). One explanation for this varying prevalence of postpartum sexual dysfunction may be the properties of scales used to measure women's sexual function. Furthermore, sexual activity of postpartum women may be influenced by cultural and social differences; leading to different results in various populations. The study findings also showed that demographic factors, including age, education, family income, breast-feeding and parity were associated with women's sexual functioning. These findings are supported by other authors $(4,28)$.
Consistent with findings of some other studies, this study demonstrated that sexual functioning of women undergoing episiotomy was no different than that of women with intact perinea $(29,30)$. Also, in this study, type of delivery was not related to sexual dysfunction among participants. However, as mentioned before, the literature shows conflicting conclusions regarding the role of cesarean delivery in protecting females from sexual problems. Similarly to our findings, some other studies showed no significant difference between sexual functioning and mode of delivery $(14,30)$. Due to concern regarding the rise in maternal requests for CS in recent years, it is recommended that these observations be further investigated in prospective, longitudinal studies.

The most prevalent sexual dysfunction among the study participants was related to their desire for sexual activity; this tendency had also been reported in another study in Iran (31). The emotional strain and fatigue of parenting may have contributed to diminished sexual desire after childbirth (30). Decreased sexual desire at three months postpartum and the following increment at six months postpartum was demonstrated by another study; however, no complete return to pre-pregnancy levels was observed (16).

In our study, women who had exclusively breast fed their infants and those for whom less than six months had passed since delivery reported more pain during intercourse. Mothers who were exclusively breastfeeding also reported greater arousal and lubrication problems than non-breast feeding mothers. 
The higher prevalence of postpartum sexual dysfunction among breastfeeding mothers is evident in other studies $(10,14)$. Breastfeeding is known to be associated with a lack of sexual desire, delay in resumption of sexual intercourse, vaginal dryness and dyspareunia $(2,3,16)$. In similar study in Iran, incidence of dyspareunia was higher among women who had breastfed their infants and those who had undergone instrumental intervention during delivery (10). Such an association was also found in a study in England (16). However, sexual dysfunction among breastfeeding mothers is not reported as universal. For example, in one study, decreased in $55 \%$ and increased in $39 \%$ of breastfeeding women (32).

Similarly to the findings of a study in Malaysia, there was gradual improvement in sexual functioning among postpartum women as time passed after birth (33). Findings of this study showed that women who had given birth more than six months ago had better sexual functioning in the domains of orgasm, satisfaction and pain. Another study in Iran also showed a significant association between amounts of time passed from delivery and improved sexual functioning scores (28). In our study, multiparous women had better sexual functioning in the domains of desire, orgasm, arousal and satisfaction. This was congruent with findings of similar study in USA (14). However, another study showed that declined sexual desire was notably impacted by a prior childbirth (30).

The logistic regression model demonstrated that the estimated probability of sexual functioning in the postpartum period was associated with exclusive breastfeeding and parity. Many other variables have been proposed by several studies as predictors of sexual functioning in postpartum women. Religion, onset of menstruation, living with partners, depression, number of children, working hours in employed women and fear of a new pregnancy were recognised as the other predictors of postpartum sexual function $(2,6,8,14,16,28$, 34 ). However, among these, a number of simple variables were used in our prediction model; this had the benefit of making the model simple and easy to use.

Similarly, findings of another study in USA showed that multiparity was associated with increased likelihood of early resumption of intercourse. Also, women who were depressed, older or exclusively breastfeeding experienced poorer sexual satisfaction (14). However, findings of a study in Nigeria showed parity and breastfeeding status were not related to increased odds of early resumption of postpartum sexual activity (4). According to data reported by a study in Netherland, sexual dissatisfaction one year after delivery associated with not being sexually active at three months of pregnancy and with mothers of an older age at the time of labour (34).

Findings of this study have several important clinical implications. Given the high proportion of women who reported postpartum sexual dysfunction in this study, we have recommended sexual and contraception counseling for pregnant and postpartum women regarding early resumption of sexual intercourse during the postpartum period. Several studies have shown that only 1 out of 4 women with postpartum sexual difficulties had consulted a health care professional $(16,29)$. Healthcare providers almost never obtain information on sexual issues from their clients and they do not have the necessary skills to manage these problems. As many medical students and nurses/ midwives in training have difficulty discussing matters of sex with clients, education for health professionals should address sexual health with respect to cultural and religious influences on sexual expression.

This study was not without limitations; it was conducted as a cross-sectional study and the baseline information about women's sexual activity was not collected in the antepartum period. So, there is no sense if reported problems were postpartum-related sexual problem or not. In addition, there are some other possible confounders of sexual function, which may influence interpretability of findings. Future research would benefit from the use of a larger sample, not only to verify these findings but also to assess the impact of other demographic/ cultural and maternal variables that may influence women's sexual functioning in the postpartum period.

\section{Conclusion}

The present findings highlight important concerns regarding female sexual functioning in the postpartum period. The majority participants had postpartum sexual dysfunction, and their sexual functioning was hindered by several factors, (e.g., breast feeding and primiparity). As relatively few women in Asian and Islamic countries report their sexual problems, clinicians should ask women about their concerns 
Original Article | Postpartum sexual functioning and its predicting

regarding postpartum sexual functioning and counsel them on this issue.

\section{Acknowledgement}

The authors would like to thank the all the women of the mentioned health centres, who sincerely assisted the researchers all through the study.

\section{Conflict of interest}

The authors declared no conflict of interest.

\section{Authors' Contributions}

Conception and design: NR, AA, RV

Analysis and interpretation of the data: NR, AA

Drafting of the article: AA

Critical revision of the article for important intellectual content: AA

Final approval of the article: NR, AA, KS, RV

Provision of study materials or patients: NR

Statistical expertise: NR, KS

Obtaining of funding: NR

Administrative, technical, or logistic support:

NR, KS, RV

Collection and assembly of data: NR

\section{Correspondence}

Dr Arman Azadi

MSc (Tarbiat Modares University, Tehran, Iran)

PhD (Tabriz University of Medical Sciences, Tabriz, Iran)

Assistant Professor

Department of Nursing,

Faculty of Nursing and Midwifery,

Ilam University of Medical Sciences,

Ilam, Iran.

Tel and fax: +988432227114

E-mail: azadi.arman@gmail.com

\section{References}

1. Johnson CE. Sexual health during pregnancy and the postpartum. $J$ Sex Med. 2011 May;8(5): 1267-1284. https://dx.doi.org/10.1111/j.17436109.2011.02223.x
2. Abdool Z, Thakar R, Sultan AH. Postpartum female sexual function. Eur $J$ Obstet Gynecol Reprod Biol. 2009 Aug;145(2):133-137. https:// dx.doi.org/10.1016/j.ejogrb.2009.04.014

3. Andrews V, Thakar R, Sultan AH, Jones PW. Evaluation of postpartum perineal pain and dyspareunia-a prospective study. Eur $J$ Obstet Gynecol Reprod Biol. 2008;137(2):152-156. https://dx.doi.org/10.1016/j.ejogrb.2007.06.005

4. Anzaku A, Mikah S. Postpartum resumption of sexual activity, sexual morbidity and use of modern contraceptives among nigerian women in jos. Ann Med Health Sci Res. 2014;4(2):210-216. https://dx.doi.org/10.4103/2141-9248.129044

5. Rogers RG, Borders N, Leeman LM, Albers LL. Does spontaneous genital tract trauma impact postpartum sexual function? $J$ Midwifery Womens Health. 2009;54(2):98-103. https:// dx.doi.org/10.1016/j.jmwh.2008.09.001

6. Leeman LM, Rogers RG. Sex after childbirth: postpartum sexual function. Obstet Gynecol. 2012;119(3):647-655. https://dx.doi.org/10. 1097/AOG.obo13e3182479611

7. Rupp HA, James TW, Ketterson ED, Sengelaub DR, Ditzen B, Heiman JR. Lower sexual interest in postpartum women: relationship to amygdala activation and intranasal oxytocin. Horm Behav. 2013;63(1):114-121. https://dx.doi. org/10.1016/j.yhbeh.2012.10.007

8. Lewis JA, Black JJ. Sexuality in women of childbearing age. $J$ Perinat Educ. 2006;15(2):29-35. https://dx.doi.org/10.1624/ 105812406x10779

9. Yeniel AO, Petri E. Pregnancy, childbirth, and sexual function: perceptions and facts. Int Urogynecol J. 2014;25(1):5-14. https://dx.doi. org/10.1007/so0192-013-2118-7

10. Dabiri F, Yabandeh AP, Shahi A, Kamjoo A, Teshnizi SH. The effect of mode of delivery on postpartum sexual functioning in primiparous women. Oman Med J. 2014;29(4):276-279. https://dx.doi.org/10.5001/omj.2014.72

11. Safarinejad MR. Female sexual dysfunction in a population-based study in Iran: prevalence and associated risk factors. Int $J$ Impot Res. 2006;18(4):382-395. https://dx.doi. org/10.1038/sj.ijir.3901440 
12. Sayasneh A, Pandeva I. Postpartum sexual dysfunction: a literature review of risk factors and role of mode of delivery. $\mathrm{Br} J$ Med Pract. 2010;3(2):316-320.

13. Shirvani M, Nesami M, Bavand M. Maternal sexuality after child birth among Iranian women. Pak J Biol Sci. 2010;13(8):385-389. https:// dx.doi.org/10.3923/pjbs.2010.385.389

14. Yee LM, Kaimal AJ, Nakagawa S, Houston K, Kuppermann M. Predictors of postpartum sexual activity and function in a diverse population of women. $J$ Midwifery Womens Health. 2013;58(6):654-661. https://dx.doi.org/10.1111/ jmwh.12068

15. World Health Organization. Pregnancy, childbirth, postpartum, and newborn care: a guide for essential practice. 2006. Available from: https://www.who.int/maternal_child_ adolescent/documents/924159084x/en/

16. Barrett G, Pendry E, Peacock J, Victor C, Thakar R, Manyonda I. Women's sexual health after childbirth. BJOG. 2000;107(2):186-195.

17. Basirnia A, Sahimi-Izadian E, Arbabi M, Bayay Z, Vahid-Vahdat S, Noorbala AA, et al. Systematic review of prevalence of sexual disorders in Iran. Iran J Psychiatry. 2007;2(4):151-156.

18. Symon A, MacKay A, Ruta D. Postnatal quality of life: a pilot study using the mother-generated index. $J$ Adv Nurs. 2003;42(1):21-29.

19. Ghanbarzadeh N, Nadjafi-Semnani M, Ghanbarzadeh MR, Nadjfai-Semnani A, NadjfaiSemnani F. Female sexual dysfunction in Iran: study of prevalence and risk factors. Arch Gynecol Obstet. 2013;287(3):533-539. https://dx.doi. org/10.1007/s00404-012-2604-z

20. Shahhosseini Z, Gardeshi ZH, Pourasghar M, Salehi F. A review of affecting factors on sexual satisfaction in women. Mater Sociomed. 2014;26(6):378-381. https://dx.doi.org/10. 5455/msm.2014.26.378-381

21. Shokrollahi P, Mirmohamadi M, Mehrabi F, Babaei G. Prevalence of sexual dysfunction in women seeking services at family planning centers in Tehran. $J$ Sex Marital Ther. 1999;25(3):211-215. doi: https://dx.doi. org/10.1080/00926239908403995
22. Rosen R, Brown C, Heiman J, Leiblum S, Meston C, Shabsigh R, et al. The female sexual function index (FSFI): a multidimensional self-report instrument for the assessment of female sexual function. $J$ Sex Marital Ther. 2000;26(2):191-208. https://dx.doi. org/10.1080/009262300278597

23. Meston CM. Validation of the female sexual function index (FSFI) in women with female orgasmic disorder and in women with hypoactive sexual desire disorder. J Sex Marital Ther. 2003;29(1):39-46. https://dx.doi. org/10.1080/713847100

24. Meston CM, Derogatis LR. Validated instruments for assessing female sexual function. $J$ Sex Marital Ther. 2002;28(S1):155-64. https:// dx.doi.org/10.1080/00926230252851276.

25. Wiegel M, Meston C, Rosen R. The female sexual function index (FSFI): cross-validation and development of clinical cutoff scores. $J$ Sex Marital Ther. 2005;31(1):1-20. https://dx.doi. org/10.1080/00926230590475206

26. Fakhri A, Pakpour AH, Burri A, Morshedi H, Zeidi IM. The female sexual function index: translation and validation of an Iranian version. $J$ Sex Med. 2012;9(2):514-523. https://dx.doi.org/10.1111/ j.1743-6109.2011.02553.x

27. Mohammadi Kh, Heydari M, Faghihzade S. Validity of the Persian version of the female sexual function index (FSFI) as an indicatorof women's sexualfunction. Payesh. 2008;7(3):269-278 [in Persian].

28. Boroumandfar K, Rahmati MG, Farajzadegan $\mathrm{Z}$, Hoseini H. Reviewing sexual function after delivery and its association with some of the reproductive factors. Iran J Nurs Midwifery Res. 2010;15(4):220-223.

29. Holanda JBdL, Abuchaim EdSV, Coca KP, Abrão ACFdV. Sexual dysfunction and associated factors reported in the postpartum period. Acta Paulista de Enfermagem. 2014;27(6):573-578. https:// dx.doi.org/10.1590/1982-0194201400093

30. Botros SM, Abramov Y, Miller J-JR, Sand PK, Gandhi S, Nickolov A, et al. Effect of parity on sexual function: an identical twin study. Obstet Gynecol. 2006;107(4):765-770. https://dx.doi. org/10.1097/01.AOG.0000207677.03235.76 
Original Article | Postpartum sexual functioning and its predicting

31. Pourakbaran E, Yazdi SAA. A study of sexual functioning and marital satisfaction in women with and without history of labor. $J$ Fundam Ment Health. 2015;17(4):202-208

32. Avery MD, Duckett L, Frantzich CR. The experience of sexuality during breastfeeding among primiparous women. $J$ Midwifery Womens Health. 2000;45(3):227-237.

33. Radziah M, Shamsuddin K, Jamsiah M, Normi M, Zahari TM, Syimah AN, et al. Early resumption of sexual intercourse and its determinants among postpartum Iban mothers. Int $J$ Reprod Contracept Obstet Gynecol. 2013;2(2):124129. https://dx.doi.org/10.5455/2320-1770. ijrcog20130603
34. Van Brummen H, Bruinse H, Van de Pol G, Heintz A, Van der Vaart C. Which factors determine the sexual function 1 year after childbirth? Int $J$ Gynaecol Obstet. 2006;113(8):914-918. https:// dx.doi.org/10.1111/j.1471-0528.2006.01017.x 